\title{
Gênero e música barroca
}

\author{
Suzanne Cusick (New York University, Nova lorque) \\ suzanne.cusick@nyu.edu \\ Tradução de Silvana Scarinci (UFMG, Belo Horizonte) \\ silvanascarinci@yahoo.com.br \\ Revisão de Lúcia Carpena (UFRGS, Porto Alegre) \\ Icarpena@terra.com.br
}

Resumo: Na Europa dos séculos XVII e XVIII, a cultura musical e aquilo que os antropólogos denominam de "sistema de sexo/gênero" eram áreas importantes para seres humanos comuns (e não filósofos) confrontarem e se engajarem com as ansiedades epistemológicas e sociais que caracterizavam a era. Este ensaio deverá explorar a miriade de relações entre gênero e cultura musical barroca, com ênfase especial nos aspectos mais exóticos destas relações - os papéis adotados pelas cortesãs, castrati e seus patrões da mais alta elite com o intuito de manter a prática musical como um meio para a representação e circulação de poder e desejo..

Palavras-chave: Música Barroca, Música e estudos de gênero, cortesãs, castrati.

\section{Gender and Baroque Music}

Abstract: In 17th- and 18th- century Europe, both musical culture and what anthropologists call the sex/gender system were important sites for ordinary human beings (not philosophers) to confront and engage with the epistemological and social anxieties that characterized the age. This paper will explore the myriad relationships of gender and Baroque musical culture, with special emphasis on the most foreign aspects of those relationships-the roles that courtesans, castrati and their most elite patrons played in ensuring that music-making was a means for both the representation and the circulation of power and desire.

Keywords: Baroque Music, Music and Gender Studies, cortesans, castrati.

\section{1 - Introdução}

0 estudo de gênero em relação à música barroca é uma nova área de pesquisa, uma área caracterizada por questões ainda sem respostas e ao mesmo tempo por sua visão crítica ou histórica. Disto resulta que não há uma narrativa completa sobre gênero e música barroca que eu possa apresentar a vocês hoje, nem mesmo algo que tente explicar a maneira pela qual gênero interagia com o amplo espectro de comportamento musical dos europeus dos séculos XVII e XVIII (e suas colônias). Uma vez que não posso almejar uma abrangência total, tratarei de introduzi-los às premissas básicas, questões e problemáticas deste novo campo, com a esperança de oferecer alguns quadros de referência que poderão enriquecer sua própria pesquisa ou execução musical. Tentarei, como fiz no início desta semana, finalizar com um estudo de caso que demonstra, por um lado, que refletir sobre as dinâmicas de gênero historicamente específicas que (in) formaram uma obra em particular pode nos ajudar a com- preender esta obra de modo semelhante àquela que seu criador e suas primeiras audiências o fizeram. Tentarei também fazer com que percebam porque todos aqueles que se interessam por música barroca em contexto (em seus possíveis significados) gostam de saber algo sobre as relações desta música com as normas de gênero do século XVII e XVIII.

Em primeiro lugar, no entanto, o que é gênero e quais são as premissas básicas e questões levantadas pelos estudos de gênero em relação à música barroca?

Gênero é um sistema de distribuição de poder social baseado nas relações humanas com fins na reprodução sexual. 0 sistema, seja qual for, depende da definição e imposição de normas sexuais (por sua vez, dependente da definição, imposição e tolerância dos desvios sexuais). Ambos os sistemas e suas normas podem ser pensados como algo produzido performaticamente, isto é, pelas 
ações das pessoas, sejam estas ações na vida real ou no mundo paralelo da representação que foi tão importante para a cristalização de um imaginário do início do período moderno. Portanto, ambas as gendered 'performances em relação à produção artística (quem compõe, interpreta, atua como empresário, poeta ou mecenas, etc) e o uso da produção artística para representar gênero são relevantes, assim como os lugares mais óbvios de interação entre as duas.

Gênero, na Europa, nos séculos XVII e XVIII, era muito heterogêneo e muitos dos seus detalhes dependiam de costumes locais. No sentido mais geral, a percepção histórica posterior sugere que normas de gênero podem ser percebidas de acordo com o eixo Norte (protestante)/Sul (católico), no qual o Norte protestante seria mais "liberado" no sentido de tratar homens e mulheres com mais igualdade, mas ainda assim com muito mais investimento na regulamentação estrita da sexualidade através do casal heterossexual do casamento burguês. Em contraste a isto, o sul católico parece mais "liberado" no sentido de reconhecer um espectro muito mais amplo de lugares para o sujeito generized, especialmente com nuances nas questões de classe e no sentido de reconhecer um espectro muito vasto de comportamento sexual fora das normas do casal heterossexual. Este contraste tem ecos em nossa época, ao menos na América anglófona, onde existe uma permanente tensão entre o chamado "feminismo liberal" (baseado nos ideais do norte protestante de igualdade de gênero dentro de um sistema determinado a normatizar a heterossexualidade) e um feminismo que se alinha com o ativismo queer num esforço de reconhecer, respeitar e assegurar igualdade para uma gama muito mais ampla dos lugares do sujeito generized e dos comportamentos sexuais.

Nos últimos vinte anos, tem surgido um interesse nas questões de gênero e sua interação com as produções de música no Barroco - na maioria das vezes estas questões surgiram a partir de uma questão básica na história das mulheres: onde estavam as mulheres na cultura musical? A resposta, é claro, é que as mulheres estavam em todos os lugares e que alguns aspectos das suas vidas musicais parecem ter sido agudamente gendered, assim como 0 gendering do comportamento musical sempre foi dependente da classe social da mulher. Ainda assim, muitas, muitas questões permanecem apenas parcialmente respondidas. Aqui estão algumas.

Quem eram os músicos profissionais, tanto mulheres quanto homens? A quem cabia o papel de intérprete, quem devia compor, quem devia dirigir as performances em público ou prepará-las privadamente? Quem exercia que tipo de papel profissional, onde e sob quais condições de trabalho? Quando o status de músico "profissional" ameaçava a reputação de uma mulher em sua continen$z a$ (auto-refreamento, e todas as virtudes femininas que ela representa)? Como as mulheres em épocas e lugares diferentes negociavam estas ameaças a sua reputação?
Quando estas ameaças frustraram o desejo das mulheres para desenvolver sua musicalidade, e quando, paradoxalmente, estas mesmas ameaças davam-lhes poder? Havia circunstâncias nas quais as mulheres eram forçadas a tornarem-se musicistas porque este era o trabalho da familia? 0 que acontecia nas familias nas quais as fiIhas eram melhores musicistas que os filhos? Uma vez que sabemos que muitas mulheres eram primordialmente instrumentistas e não cantoras, por que tantas fontes européias do século XVII (diários, poemas encomiásticos e objetos do gênero) representam a musicalidade feminina como se fosse equivalente à expressão vocal? E por que esta impressão aparentemente falsa e limitada persistiu por tanto tempo?

De que modo a produção de música sacra possuía uma carga de gênero (gendered)? Quem podia interpretar ou dirigir performances na igreja? Quem podia compor música para a igreja? Sabemos que as mulheres podiam interpretar, reger e compor música sacra em conventos, muitas vezes com tanto virtuosismo que as performances musicais em suas comunidades tornavam-se atrações turísticas provocando reações nas audiências que combinavam êxtase musical e espiritual com fantasias eróticas sobre as mulheres que tocavam e cantavam por detrás das grades, supostamente ocultas pelo véu monástico. ${ }^{2}$ Além disto, sabemos também que a vida das mulheres nos monastérios era extremamente rica em termos musicais, num nível que estas audiências masculinas jamais poderiam conhecer. Alguns conventos eram notórios pela execução diária de canto e dança e por apresentações de teatro musical sobre assuntos sacros com cena e vestuário elaborados - performances para as quais a elite de mulheres laicas tinha acesso freqüente, embora fossem proibidas ao acesso masculino. Em vista desta rica tradição católica e da rica tradição das execuções musicais nos orfanatos de Veneza, podemos nos perguntar sobre as implicações do protestantismo na vida musical das muIheres. Até que ponto o protestantismo limitara as oportunidades para a auto-expressão musical das mulheres?

Como a questão de gênero moldou a relação do mecenato musical? Sabemos [a partir de Dell'Antonio e outros] que os homens de elite, especialmente os que se tornavam nobres recentemente, demonstravam (performed) seu gosto refinado como 'colecionadores' das performances de outros, através de retratos, manuscritos de cantatas, diários descrevendo performances que eles assistiam. Sabemos que os próprios membros destas mesmas elites "colecionavam" os músicos, especialmente castrati e cortesãs ou musicistas a quem tratavam como cortesãs. Poderíamos supor que, paralelamente, mulheres mecenas "colecionavam" retratos, manuscritos, guardavam lembranças de performances e pessoas? ${ }^{3}$ Sabemos que em meados do século XVII, em Roma, Olimpia Aldobrandini competia com mulheres das familias Barberini, Borghese e Pamphili pelo direito de declarar que seus concertos privados eram os melhores da cidade e que ela mesma acusava publicamente de prostitutas as cantoras que the 
tratavam com desrespeito (BROSIUS, no prelo). Mas os documentos pessoais e financeiros das mulheres que não eram chefes de estado são raros ou imperfeitamente preservados e não sabemos quase nada sobre o mundo musical dirigido por mulheres de elite que não pertenciam à corte; portanto, não sabemos (ainda) se havia universos paralelos de produção musical feminina em meados do Barroco que fossem análogos ao que conhecemos sobre o início do período. Tampouco sabemos em que extensão homens e mulheres musicistas no Barroco continuaram a servir - da maneira que serviram na era das cortes do final do século XVI e início do XVII - como objeto de troca para ser barganhado por seus patrões numa economia de presentes que servia mais diretamente aos interesses dos patrões do que aos interesses dos músicos. Até que ponto os músicos, tanto homens quanto mulheres, viravam o jogo e controlavam seus patrões cujas paixões explorariam em busca de sua mobilidade social ascendente?

Como a cultura que tratava a música como uma realização feminina emerge das práticas do Barroco e pré-Barroco? A evidência dos livros de conduta que circulavam entre as novas classes nobres sugere que o fazer musical, especialmente a execução instrumental ou seu treino, era freqüentemente defendido para encorajar a modéstia feminina, pois esta prática exigia que ela rebaixasse o olhar para seu instrumento ou para a música escrita que ela lia. ${ }^{4}$ A prática musical era quase tão boa quanto a leitura ou 0 bordado; todos eram comportamentos que reforçavam e demonstravam as virtudes da continenza, isto é, o autorefreamento. Além disto, a prática musical podia ser um meio tolerável para a auto-expressão feminina, pois nem a execução instrumental nem o canto era o mesmo que a fala: a prática musical não violava a norma cultural que exortava a mulher a ser silenciosa. Mas ainda não sabemos quando, onde e sob quais circunstâncias tal prática musical privada e amadora pode ter confinado a vida das muIheres. Tampouco sabemos o suficiente sobre quando, onde e sob quais circunstâncias a prática musical dava poderes ${ }^{5}$ às mulheres - seja ao possibilitar-lhes um escape para a expressão emocional (como se tornou um lugar comum na cultura da sensibilité que surgiu no final do século XVIII na França), ou ao ensinar-Ihes o hábito mental de explorar os paradoxos do sistema de gênero para servir a seus próprios fins. E conhecemos quase nada sobre as musicalidades com carga de gênero (gendered) entre as pessoas que não faziam parte da elite, as pessoas cujas histórias os musicólogos têm a tendência de não conhecer.

0 que poderiamos pensar de Francesca Caccini e sua música, se tivéssemos melhores respostas às questões que agora temos? Ou de Barbara Strozzi, Isabella Leonarda, Antonia Bembo, Elisabeth Jacquet de la Guerre? E o que faríamos com Buxtehude, Handel ou Bach?

0 que poderiamos pensar das maneiras pelas quais gênero é representado na música barroca, se conhecêssemos melhor o sistema no qual os criadores (homens e mulheres) destas representações viviam? Parte da pesquisa dos últimos vinte anos (incluindo meu próprio trabalho inicial e o de Susan McClary) mostrou tendências de ler estas representações através do viés contínuo da musicologia norte-americana de modo trans-histórico e descontextualizado - isto é, através de nossa tendência em escrever histórias da música como se os sentidos de várias representações codificassem verdades universais sobre gênero que pessoas como nós, vivendo num mundo completamente diferente, pudéssemos compreender (MCCLARY, 1991 e CUSICK, 1992). Este tipo de crítica é fundamentalmente não-histórica - o que não é algo necessariamente ruim, desde que se reconheça que isto não nos diz tudo que poderiamos querer saber ao pensarmos sobre gênero em relação à música barroca.

\section{2 - Gênero naquele tempo não era como gênero hoje}

Quase quarenta anos de estudos feministas em várias disciplinas demonstraram que gênero, sexualidade e diferença sexual são todos construídos socialmente e são sempre típicos de determinadas culturas, em momentos históricos determinados. A partir dos trabalhos dos historiadores da medicina, Thomas Laqueur e Katherine Park, podemos compreender que gênero na Europa pré-iluminista não era o mesmo que gênero hoje (em qualquer lugar), e tampouco sexualidade, ou o que possamos imaginar que fosse o fato biológico da diferença sexual (LAQUEUR, 1990 e PARK, 1997). De fato, historicizar gênero e sexo no Barroco nos leva para um mundo muito, muito estranho, muito diferente do nosso. Aqui estão as premissas básicas através das quais gênero e sexo foram conceitualizados no Barroco, do modo como Laqueur e Parks as desenterraram cuidadosamente dentre dúzias (senão centenas) de tratados médicos, sátiras e livros de conduta.

Desde pelo menos o século II a.C. até o final do século XVIII, a opinião médica dominante na Europa ensinava que havia somente um sexo e dois gêneros. Anatomicamente, mulheres eram homens incompletos, sua genitália tendo permanecido dentro do corpo (e viradas ao avesso) por causa de calor insuficiente no útero de suas mães. Portanto, mulheres e homens não eram sexos opostos. Eles eram respectivamente variantes perfeitas e imperfeitas do mesmo sexo. A hierarquia de gênero que valorizava os homens acima das mulheres simplesmente refletia 0 valor maior dado à perfeição em oposição à imperfeição. Pessoas com corpos de mulheres eram naturalmente mais fracas em inúmeras formas. Fraqueza poderia se tornar, para algumas pessoas, inferioridade ou mesmo monstruosidade. Uma das razões pelas quais muitos homens na Europa do início da modernidade preferiam (e mesmo defendiam) a sodomia ao invés da heterossexualidade era o desejo de evitar o contato físico íntimo com seres humanos intrinsecamente inferiores (monstruosos).

Em função de Ihes faltarem genitália externa adequada, os corpos das mulheres eram incapazes de gerar tanto calor quanto os homens. Elas eram "naturalmente" frias e portanto úmidas, vazando os fluídos insuficientemente 
inflamáveis de seus corpos (os humores do sangue, fleuma, bilis amarela e negra) como o leite, sangue menstrual e lágrimas. Os corpos dos homens, ao contrário, eram "naturalmente" quentes e secos, a espuma de seu sêmen era o sinal de um fluído corporal corretamente inflamável.

Esquentar o corpo de uma mulher, especialmente (mas não exclusivamente) próximo a seus genitais, era um pré-requisito para sexo bem sucedido e para o orgasmo, o que por sua vez, era pré-requisito para a liberação da semente que resultaria em gravidez. Mas se a quantidade suficiente de calor deixava uma mulher pronta para encontros sexuais, calor excessivo poderia transformar seu corpo humano incompleto no corpo humano plenamente desenvolvido de um homem. 0 primeiro sinal de calor excessivo era a disfunção menstrual; mas também calor excessivo podia significar um corpo pronto para sexo, ou pronto para transformar-se no corpo de um homem. Deste modo, ao controlar a temperatura do corpo da mulher, controlava-se seu uso reprodutivo, sua autonomia sexual e seu gênero. Para manter o calor de seus corpos numa temperatura apropriadamente moderada, meninas e muIheres eram aconselhadas a evitar comer carne, beber vinho ou fazer exercícios extenuantes. Acreditava-se que mulheres atletas, dançarinas e cantoras colocavam sua capacidade reprodutiva em risco porque estas atividades aqueciam seus corpos de forma antinatural; em função de seus corpos quentes, logicamente tais mulheres podiam ser imaginadas sexualmente mais disponiveis que outras mulheres e mais suscetiveis à mutação miraculosa do hermafroditismo que as transformaria em homens.

Por causa de seus corpos imperfeitos, mulheres eram naturalmente mais fracas que os homens. ${ }^{6}$ Alguns acreditavam que sua temperatura fria causava inferioridade intelectual, depravação moral, uma tendência inata a enganar e apetite sexual voraz. Homens que passavam muito tempo com mulheres eram considerados efeminados. Mesmo quando seu excessivo desejo heterossexual era o que levava estes homens a freqüentarem prostitutas, cortesãs, amantes ou suas próprias esposas. Homens com uma sexualidade forte que desejavam ou necessitavam ser percebidos em sua masculinidade, esforçavam-se por se envolver em atividades tipicamente masculinas, como comércio, caça, política e guerra, e muitos deles preferiam buscar alívio sexual com outros homens (normalmente mais jovens) do que serem vistos próximos demais das mulheres.

Acreditava-se que danos à genitália de um menino ou homem, causado intencionalmente, por acidente ou doença, reduzia a capacidade deste corpo em produzir calor. Portanto, tais homens, "naturalmente" mais frios, eram também efeminados. A castração de um menino negava a ele o último impulso de calor que faria dele um homem, deixando-o numa espécie de lugar intermediário - nem homem nem mulher, mas com um terceiro gênero, o menino eterno. Como eterno menino, no entanto, ele seria visto como efeminado, naturalmente mais sensual do que outros homens, mais inclinado à volúpia e à moral dúbia.
Tão estranhas e contrárias à intuição quanto possam parecer estas idéias, elas apontam para um mundo que compartilha uma caracteristica com o amplo espaço cultural rotulado pela palavra "queer" na América do Norte contemporânea. Gênero neste sistema é extremamente relativo. 0 gênero de uma pessoa (e mesmo seu sexo) pode depender tanto do comportamento quanto do acaso do nascimento, e, por um lado, é algo muito mais literal do que qualquer coisa imaginada nas teorias do final do século XX sobre 'performatividade' de gênero. Além disto, como Stephen Greenblatt notou, "uma conseqüência do [esquema de um só sexo] é um homo-erotismo aparente em toda sexualidade (GREENBLATT, 1988, p. 92)."

Para mim, o conhecimento desta surpreendente concepção extremamente fluída da relação entre gênero e sexo apresenta grandes promessas, pois ela libera o estudo de gênero e música no Barroco de uma preocupação com a vida musical das mulheres, o que poderia tornar todo o campo de pesquisa parecer marginal, irrelevante aos homens. Como Wendy Heller eloqüentemente demonstrou, o modelo Laqueur/Park provê uma explicação intuitiva para o predomínio de mulheres surpreendentemente fortes, freqüentemente até masculinas e de homens surpreendentemente fracos, efeminados, como personagens centrais da ópera veneziana: mulheres quentes, assertivas, (às vezes mesmo masculinizadas) e homens frios, sensuais e efeminados eram amantes previsíveis na Europa barroca (HELLER, 2003). Além disto, esta compreensão de gênero barroco fornece um contexto com um foco agudo para a complexidade freqüentemente estonteante do jogo de gêneros na ópera veneziana. Em suas múltiplas camadas de cenas com vestimentas cruzadas, e, algumas vezes, papéis com cruzamento de vozes que parece misturar irremediavelmente as identidades de gênero dos personagens, estas óperas literalmente encenavam o sistema de gênero basicamente instável no qual as audiências do século XVII acreditavam - permitindo a estas audiências contemplar as implicações da instabilidade de gênero na vida política. Assim o modelo de Laqueur/Parks, quando acompanhado de exaustiva leitura da literatura panfletária do século XVII sobre feminilidade, possibilitou a Heller explorar em grande profundidade os meios pelos quais a instituição da ópera interagia com o sistema de sexo/gênero da Veneza setecentista.

\section{3 - Música barroca como troca erótica}

0 modelo de Laqueur/Parks também ilumina o modo em que a música funciona como meio para as trocas de prazer erótico. Eu pretendo usar a palavra "erótico" com o sentido que funde as idéias similares de Platão, Freud e a poeta americana Audre Lorde, os quais usam o conceito de eros para referirem-se à força vital uma energia vital baseada nos sentidos que traz a alegre consciência de se estar vivo e não morto. ${ }^{7}$ Trata-se da experiência humana que inclui, mas não está de forma alguma limitada, ou mesmo especificamente focada nos atos que usualmente chamamos de "sexo." Esta função da música como meio para a circulação de energia eró- 
tica e prazer me parece ter sido institucionalizada no Barroco italiano, tornando-se um elemento central da sensibilidade barroca.

A música tem sido associada com experiência erótica desde pelo menos a época de Platão. Tanto em sua República quanto em suas Leis, Platão argumenta que o estado devia controlar a música, pois certos modos poderiam estimular um perturbador desejo físico e uma inclinação (somente) à auto-satisfação em delícias sensuais. Ao ameaçar a capacidade para a razão e assim "suavizar" a alma a ponto de enfraquecer o desejo de lutar, quando necessário, tais modos gravavam na alma de executantes e ouvintes padrões afetivos que pareciam perigosos para membros da classe política. Estes padrões desorganizavam o equilíbrio delicado das qualidades de gênero que Platão acreditava que deveriam caracterizar os líderes de um estado ideal, produzindo uma feminização inapropriada e disempowering ${ }^{8}$ tanto em muIheres quanto em homens. Outras versões da ansiedade de Platão sobre o poder erótico da música proliferam na literatura ocidental, tanto religiosa quanto secular. 0 tema veio à tona dramaticamente no discurso musical profissional no início do século XVII, especialmente nas batalhas retóricas vociferadas contra a textura das linhas vocais e novidades harmônicas que compositores como Monteverdi, Peri e os Caccini exploraram como meios de transformar a música como discurso de verdades cósmicas numa arte de persuasão e expressividade emocional. ${ }^{9} \mathrm{~A}$ relação entre a experiência musical e a experiência erótica foi avidamente (ou também ansiosamente) explorada durante o período histórico que agora chamamos de Barroco. Realmente, podemos também argumentar que a famosa musica segreta na corte dos Este em Ferrara, o mais antigo conjunto imbuído da intenção específica de produzir meraviglia musical, institucionalizou a ligação entre o musical, o erótico e o político que já havia sido previsto por Platão. Supostamente criado para servir a jovem noiva do Duque de Este e sua comitiva, o conjunto era formado por quatro mulheres de boas origens e um nobre. ${ }^{10}$ Estas mulheres, cantoras e instrumentistas virtuoses, são consideradas freqüentemente como as primeiras mulheres musicistas "profissionais." Pagas com altos salários, garantidas por dotes extremamente generosos, nobres maridos e apartamentos no palácio de Este, elas serviam às mulheres da familia Este participando com elas em peças e balletti produzidas somente para o prazer da família mais próxima. Mas elas também serviam às ordens do Duque, cantando para os convidados que ele tentava agradar compartilhando os prazeres auditivos da vida doméstica de sua família. $\mathrm{Na}$ realidade, o musica segreta não tinha nada de secreto; quase todos os que pertenciam a uma determinada classe eram convidados a escutá-las, e quase todos que escreveram cartas relatando a experiência, focalizaram os mesmo detalhes. As damas cantavam música espetacularmente ornamentada, combinando cada gesto visível do rosto, mãos e corpo com o afeto das palavras que elas cantavam. Quando seus convidados surpreendiam-se com o virtuosismo das aparentes improvisações, o Duque orgulhosamente fazia circular o libro dei tirati, um livro manuscrito contendo centenas de canções de seu repertório, para demonstrar que suas inter- pretações não eram de forma alguma improvisadas, mas sim execuções perfeitas de ornamentos compostos para elas pelos dois homens encarregados de liderar o conjunto - Ippolito Fiorini e Luzzasco Luzzaschi.

Todas estas descrições possuem uma carga erótica, sobre a qual alguns autores têm interpretado como algo provocado apenas pela presença física das mulheres em performance, as quais costumeiramente não fariam música fora de seus próprios círculos domésticos. Mas ao ler mais profundamente os tratados médicos do século XVI, Bonnie Gordon e outros demonstraram como estas execuções devem ter sido vistas como algo claramente sexualizado (GORDON, 2004 e TOMLINSON, 1993). Em primeiro lugar, a literatura prescritiva desde a era clássica aconselhava as mulheres a demonstrarem sua castidade através do silêncio. A boca fechada da parte superior do corpo simbolizava a boca fechada de suas partes inferiores. Assim, para mulheres de boas origens, quebrarem seu silêncio de forma tão extravagante em frente a estranhos, implicava na possibilidade de que elas estariam sexualmente disponíveis. Em segundo lugar, como Gordon e Gary Tomlinson demonstraram, alguns médicos do século XVI acreditavam que a voz era uma substância que era pressionada para fora do corpo com a respiração; esta substância vibrante penetrava o ouvido, provocando a experiência do mesmo afeto no corpo do/a ouvinte com que o/a orador/a ou cantor/a impregnara sua voz. Assim, os ouvintes desta musica segreta que escreveram estas descrições poderiam muito bem ter tido a experiência de terem sido penetrados - e, portanto feminizados - pelas vozes das mulheres que se apresentavam sexualmente disponiveis. Em terceiro lugar, estas mulheres articulavam os deslumbrantes ornamentos de suas canções com uma técnica chamada gorgheggiando, na qual mesmo as mais curtas notas eram articuladas pelo abrir e fechar extremamente rápido das cordas vocais que interrompiam e reiniciavam a passagem do ar. A cada uma destas articulações, uma cantora controlava o equilíbrio entre silêncio e som na sua própria apresentação pessoal, como se em cada momento ela controlasse a abertura e fechamento de seu corpo; deste modo ela apresentava através de sons musicais claros, sua habilidade em controlar sua castidade. Talvez ainda mais excitante fosse o fato de acreditar-se que gorgheggiando era produzido pela fricção constante e tremulante não das cordas vocais, mas da glote - um órgão que ao controlar o acesso à parte superior da garganta era considerado equivalente ao órgão que por sua vez controlava o acesso à garganta inferior do corpo - o clitóris, o qual fora recentemente descoberto pelo médico Reynaldo Colombo como a localização principal do prazer feminino. ${ }^{11}$ Deste modo, o canto com extravagante gorgheggiando poderia facilmente ter impressionado os ouvintes como o som do prazer auto-erótico de uma mulher e talvez até como o som do orgasmo feminino. Estas chocantes implicações sexuais das performances do musica segreta eram, no entanto, apresentadas para suas audiências sob a firme autoridade do Duque. A circulação 
ostensiva que fazia do livro das músicas que as mulheres cantavam assegurava que seus convidados compreendessem que, em Ferrara, a musicalidade, a sexualidade e 0 corpo das mulheres eram controlados pelos homens: por homens que compunham música para elas, escreviam e ensinavam-lhes os ornamentos e dirigiam seus gestos e também pelo próprio Duque, cujo prazer elas serviam. Podemos argumentar também que quando o Duque apresentava seu musica segreta doméstico aos homens que o visitavam, ele explorava os temores de feminização destes homens. Proporcionando-Ihes a experiência do êxtase auditivo numa situação que ele controlava, o Duque se transformava no verdadeiro autor de sua feminização e seu prazer; assim o espetáculo ostensivo do controle patriarcal sobre os corpos das mulheres também demonstrava o controle do Duque sobre os corpos dos homens. Ao relermos então estas performances através das idéias contemporâneas de gênero e sexo, elas revelam-se como meios eficazes de assegurar a afirmação de autoridade absoluta do Duque sobre seus súditos - afirmação essencial de um soberano.

A ligação entre erotismo musical e sexual com o disempowerment político tornar-se-ía um tropo importante em escritos ocasionais sobre música nas próximas gerações, a longevidade do tropo certamente reforçada pela persistência da instituição musical que o musica segreta provavelmente teve a intenção de evocar - a prática musical intencionalmente erótica de trabalhadores do sexo do século XVI e XVII. ${ }^{12}$ Fossem elas prostitutas analfabetas ou elegantes e eruditas cortesãs, as mulheres de vida independente que proporcionavam prazer erótico para os homens como profissão quase sempre faziam música para ou com seus clientes. Dado os efeitos sobre o calor do corpo, a prontidão e abertura sexuais, tal prática musical compartilhada pode ter sido vista como uma forma de preliminar sexual. Ou pode ter sido vista como um deslocamento socialmente aceitável de erotismo, distanciada de outros tipos de intimidade que poderiam causar gravidez, doenças ou queda espiritual, substituída então por um meio de deleite compartilhado que podia enaltecer tanto a saúde espiritual quanto somática de todos os envolvidos. Tal noção poderia explicar como o cavalheiro florentino que eu mencionei em minha palestra na segunda-feira poderia ter imaginado escapar da condenação à morte ao descrever a si mesmo como tendo sido violentado pela música de uma freira, forçado à paixão que "era como o amor," mas não como o amor carnal porque "ele se apaixonara pela beleza interior de seu espírito" que se revelara na sua música instrumental e vocal. ${ }^{13}$ Uma paixão que era "como o amor," mas não exatamente como amor carnal, parece ter permeado os espaços nos quais fazia-se música de câmara durante todo o século XVII.

No estudo ainda no prelo sobre o castrato Atto Melani, de meados do século XVII, Roger Freitas usa o modelo de Laqueur/Parks para explorar a fusão do musical e do erótico na paixão barroca pelos castrati (FREITAS, no prelo, capítulo 4). Deste modo ele pôde explicar como os castra- ti pareceriam tanto membros de um terceiro gênero sem idade, suspenso para sempre em corpos que retinham as belas qualidades comuns aos meninos e às mulheres (incluindo suas vozes) assim como sua tendência efeminada ao excesso sexual. Uma vez que eles não eram meninos vulneráveis, mas homens completamente adultos, castrati podiam, portanto servir como objetos seguros de desejo pederasta para os homens que preferiam evitar os efeitos espiritual e fisicamente contagiosos dos contatos sexuais com as mulheres. Freitas nos apresenta ampla evidência de ligações homossexuais entre castrati e seus patrões (o cantor romano Marc'Antonio Pasqualini com o Cardinal Anonio Barberini, Pistoian Atto Melani com Carlo II di Gonzaga-Nevers, que era Duque de Mântova nos anos de 1650, e o florentino Francesco de Castris com o Grand Principe Ferdinando II de' Medici no final do século XVIII). Tais ligações eram extremamente vantajosas para as carreiras musicais dos cantores, muitas vezes mais vantajosas que suas ligações igualmente comuns com mulheres (a quem eles ofereciam uma companhia agradável, o prazer visual da beleza infantilizada e a possibilidade de encontro sexual sem o risco de gravidez). Através do entrelaçamento de seus talentos musicais e eróticos, alguns castrati tornavam-se hábeis para adquirir terras e riqueza pessoal suficiente que Ihes permitia afastarem-se do que muitos consideravam a degradação da destreza do canto virtuosístico profissional.

0 trabalho de Freitas possui implicações mais amplas. Primeiro, ele parte do estudo da música na cultura cortesã para mostrar que as culturas de performance vocal na Itália do século XVII (e nas performances vocais de italianos do século XVII no exterior) estavam saturadas do que poderíamos chamar, a partir de Freud, de um erotismo polimorficamente perverso no qual tanto homens quanto mulheres podiam ser sujeitos e objetos de desejo. Em segundo lugar, ele constrói sobre a afirmação de Martha Feldman a idéia de que nos séculos XVII e XVIII "artistas nunca desapareciam completamente em seus personagens" para mostrar que no século XVII, pelo menos os castrati recebiam os papéis masculinos principais porque seu lugar efeminado suspenso fazia com que parecesse "natural" [apropriado] representar homens apaixonados (FELDMAN, 2007). Portanto, ele argumenta, os personagens de Nero e Ottone em L'incoronazione di Poppea de Monteverdi eram logicamente representados por castrati porque eles eram homens que tinham sido efeminados por sua paixão por Poppea. Mas como homens efeminados, eles não eram totalmente repugnantes para as mulheres. Ao contrário, eles eram previsíveis objetos de fantasia para o desejo dos ouvintes homens e mulheres, suas vozes trinando tanto a representação do glorioso desconhecimento do gênero, idade e capacidade sexual de seus corpos quanto a sua capacidade de execução virtuosística dos ornamentos que eram vistos como excesso às limitações dos sentidos semânticos de uma ária. Como sabemos que as práticas e o repertório centrado na cultura vocal italiana analisado por Freitas eram, na verdade, exportados 
para o amplo Império dos Habsburgo, para as cidadesestado de língua alemã e para a Inglaterra do final do longo século XVII, o trabalho de Freitas nos desafia a confrontar o erotismo imanente na música italianizada de Buxtehude, Handel e Bach.

Mas este mesmo desafio aponta para as limitações na maneira que os musicólogos têm, até agora, tentado compreender a música barroca através da visão de Laqueur e Parks de gênero barroco. Tão atraente quanto possam ser os trabalhos de Freitas, Heller, Feldman e Gordon, eles até agora têm restringido seus esforços à música vocal, deixando-nos um vasto oceano não demarcado sobre a questão de como esta compreensão historicizada do gênero no barroco possa se aplicar à execução instrumental. Teria sido a cena da música de câmara tão carrega- da eroticamente que mesmo na execução de variações numa viola, alaúde ou cravo, ou mesmo na performance de um trio sonata como música de fundo para uma refeição, por ela trafegava a força vital do prazer erótico, proporcionando uma oportunidade para o erótico ser sublimado? Seria a sublimação da carga erótica da música vocal barroca o elemento crucial da teologia jesuítica da música, que ensinava que a música poderia conduzir o espírito à contemplação do divino? Quanto a isto, como a carga erótica da experiência musical ou a compreensão de gênero e sexo como categorias intrinsecamente instáveis teria conduzido à veneração luterana de um Jesus feminino que permeia as cantatas J.S. Bach? Até onde sei, estas são percepções que ninguém pode no momento responder, mas são questões com grande potencial para a pesquisa futura.

\section{Referências}

BALDAUF-BERDES. Women Musicians of Venice: Musical Foundations, 1525-1855. Oxford: Oxford University Press, 1993.

BROSIUS, Amy. 'Il suono, lo sguardo, il canto': The Function of Portraits of Mid-Seventeenth-Century Virtuose in Rome." Italian Studies 63, 2008, no prelo. andamento.

The Culture of Singing in Barberini Rome. Tese de doutorado, New York University, em

CUSICK, Suzanne G. Vocality, Power and Female Bodies in Early Modern Italy. In Attending to Early Modern Women: Crossing Boundaries, ed. Adele Seeff. Newark: University of Delaware Press, 2000.

. Gendering Modern Music: Thoughts on the Monteverdi-Artusi Controversy. Journal of the American Musicological Society 45, 1993, p. 1-25.

DOLCE, Ludovico. L'istitutione delle donne de Ludovico Dolce. Veneza: Gabriele Giolito de Ferrari, 1545.

FELDMAN, Martha. Opera and Sovereignty: Transforming Myths in Eighteenth-Century Italy. Chicago: University of Chicago Press, 2007.

e GORDON, Bonnie, eds. The Courtesan's Arts: Cross-Cultural Perspectives. Oxford: Oxford University Press, 2006.

FREITAS, Roger. Portrait of a Castrato: Politics, Patronage and Music in the Life of Atto Melani. Oxford: Oxford University Press, no prelo.

FREUD, Sigmund. Beyond the Pleasure Principle, and Other Writings. Trad. John Reddick com introdução de Mark Edmundson. London and New York: Routledge, 2003.

GORDON, Bonnie. Vocal anatomies: mouths, breath, and throats in early modern Italy. In Monteverdi's Unruly Women: The Power of Song in Early Modern Italy. Cambridge: Cambridge University Press, 2004.

GREENBLATT, Stephen. Shakespearean Negotiations: The Circulation of Social Energy in Renaissance England. Berkeley: University of California Press, 1988, p. 92

GUASCO, Annibale. Ragionamenti ad Lavinia sua figliuola della maniera di governarsi in corte. Turin: eredi di Bevilacqua, 1586. Trad. em inglês: Discourse to Lady Lavinia, His Daughter: concerning the manner in which she should conduct herself when going to court as lady-in-waiting to the Most Serene Infanta, Lady Caterina, Duchess of Savoy. Chicago: University of Chicago Press, 2003.

HELLER, Wendy. Emblems of Eloquence: Opera and Women's Voices in Seventeenth-century Venice. Berkeley: University of California Press, 2003.

KENDRICK, Robert. Celestial Sirens: Nuns and Their Music in Early Modern Milan. Oxford: Oxford University Press, 1996. 
LAQUEUR, Thomas. Making Sex: The Body and Gender from the Greeks to Freud. Cambridge: Harvard University Press, 1990.

LORDE, Audre. "Uses of the Erotic: The Erotic as Power," ensaio apresentado na "Fourth Berkshire Conference on the History of Women", Mount Holyoke College, 25 de agosto de 1978, in Sister Outsider: Essays and Speeches by Audre Lorde, com novo prefácio de Cheryl Clarke. Berkeley: The Crossing Press, 2007, p. 53-59.

MONSON, Craig. Disembodied Voices: Music and Culture in an Early Modern Convent. Berkeley: University of California Press, 1995.

PARK, Katherine. The Rediscovery of the Clitoris. In The Body In Parts: Fantasies of Corporeality in Early Modern Europe, ed. David Hillman e Carla Mazzio. Nova lorque: Routledge, 1997, p. 171-194.

PLATÃO. The Symposium e The Phaedrus: Plato's Erotic Dialogues. Trad. com introdução e comentários de William S. Cobb. Albany: State University o New York Press, 1993.

REARDON, Colleen. Holy Concord within Sacred Walls: Nuns and Music in Siena, 1575-1700. Oxford: Oxford University Press, 2002.

TOMLINSON, Gary. Music and Renaissance Magic: Toward a Historiography of Others. Chicago: University of Chicago Press, 1993.

WEAVER, Elissa. Convent Theatre in Early Modern Italy: Spiritual Fun and Learning for Women. Cambridge: Cambridge University Press, 2002.

\section{Notas}

1 N.T.: Preferi não traduzir a palavra gendered por "generisada," como já foi usado por outros tradutores, por julgar o anglicismo demasiado estranho em nossa língua.

2 Sobre performance musical nos conventos, ver MONSON, 1995; KENDRICK, 1996; REARDON (2002); e WEAVER (2002). Sobre a cultura de performance das mulheres fora do claustro abrigadas nos orfanatos municipais de Veneza, ver também BALAUF-BERDES (1993).

3 Amy Brosius argumenta que as mulheres o faziam em BROSIUS, 2008.

40 livro de conduta mais freqüentemente reeditado foi L'istitutione delle donne de Ludovico Dolce (1545), o qual especificava que fazer música moderadamente era apropriado para meninas e mulheres. Annibale Guasco elaborou ainda mais esta opinião ao ligar a prática musical à leitura e à costura em seu Ragionamenti ad Lavinia sua figliuola della maniera di governarsi in corte (1586). 0 texto de Guasco está disponivel em tradção inglesa de Peggy Osborne sob o titulo Discourse to Lady Lavinia, His Daughter: concerning the manner in which she should conduct herself when going to court as lady-in-waiting to the Most Serene Infanta, Lady Caterina, Duchess of Savoy (2003).

5 N. T.: no original, empowered. Alguns tradutores usaram o neologismo empoderado, o que prefiro evitar.

6 Para o sumário mais atualizado sobre masculinidades no Barroco, ver FREITAS, no prelo.

7 PLATÃO, 1993; FREUD, 2003; LORDE, 2007, p. 53-59.

8 N.T.: Aqui também tento evitar o anglicismo "desempoderador", já usado em algumas traduções brasileiras.

9 Um exemplo bem conhecido é o conjunto de documentos que constituem a controvérsia Monteverdi/Artusi, os quais são inundados pela ansiedade do poder erótico da música. Ver CUSICK, 1993, p. 1-25.

10 Para os documentos primários sobre este conjunto, ver os apêndices de NEWCOMB, 1980. As análises mais recentes sobre a dinâmica de poder do conjunto está em WISTREICH, 2007, p. 239-251.

11 PARK, 1997. Sobre as implicações do trabalho de Park para as idéias do início do Barroco sobre o canto, ver GORDON, 2000, capitulo 1 e CUSICK, 2000.

12 Para maiores informações sobre este assunto, ver os ensaios em FELDMAM, 2006 e BROSIUS, no prelo.

13 Uma lista dos doze pontos que Sinolfo Ottieri fez em sua defesa encontra-se no Archivio di Stato de Florence, Otto di guardia e balia 2793, fasc. 2, f. 26r. Aqui eu resumo os pontos nove e dez, pontos que são ecos próximos do testemunho de Jacopo Cicognini e Innocentio Rucellai sobre Sinolfo Ottieri, que foi acusado de estuprar Suora Maria Vittoria Frescobaldi, em sua cela no Monastério di Santa Verdiana. Frescobaldi era conhecida como a melhor cantora de Florença. Sua professora era Francesca Caccini. Apesar das testemunhas nunca mencionarem-na pelo nome, Rucellai declarou que escutou a idéia de que um amador poderia ser "penetrado" e induzido a sentir uma paixão semelhante ao amor por uma performance virtuosistica discutida na casa da própria Francesca Caccini, compartilhada por seu marido Giovanni Battista Signorini. 
Suzanne Cusick é professora de Música da New York University, instituição na qual atualmente coordena o Programa de Pós-Graduação em Música. Ph.D. em Música pela University of North Carolina (1975) e bacharel em Belas Artes pela Newcomb College (1969), a pesquisadora publicou importantes trabalhos nas seguintes áreas: a relação entre o fazer musical, identidade e corporeidade; abordagens feministas sobre história e crítica musical; estudos sobre homossexualismo e música. Em breve publicará, pela University of Chicago Press, uma monografia sobre Francesca Caccini, cantora, professora e compositora italiana do início do século XVII. Recebeu algumas das mais importantes bolsas de estudos internacionais, como o Frederick Burkhardt Residential Fellow at Villa I Tatti e bolsa para desenvolver pesquisa na Harvard University Center for Italian Renaissance Studies (2001-2002). Foi coordenadora do Gay and Lesbian Study Group da American Musicological Society e integrou o corpo editorial do periódico dessa associação.

Silvana Scarinci realiza um pós-doutorado na UFMG, onde se dedica à pesquisa e ensino das teorias e práticas relacionadas à música barroca. Em 2008 publica o livro Safo Novella: uma poética do abandono nos lamentos de Barbara Strozzi (Veneza 1619-1677), pelas editoras EDUSP/Algol. 0 livro é acompanhado de um CD com Marilia Vargas, Luís Otávio Santos, André Cavazotti, Silvana Scarinci e Sérgio Álvares. Em 2001, fundou o grupo Anima Fortis, grupo especializado em música escrita por mulheres do período Barroco, o qual foi premiado pela associação norte-americana Early Music América em 2002. Tem participado de várias produções de ópera barroca no Brasil e Estados Unidos, destacando-se / lavori persi sob a direção de Nigel North, apresentado em 2002 no Bloomington Early Music Festival, EUA; Combattimento di Tancredi e Clorinda (Nicolau de Figueiredo dirigindo a Camerata Antiqua de Curitiba) e L'Orfeo de Monteverdi, no Teatro Municipal do Rio de Janeiro, sob direção de Marcelo Fagerlande. Foi coordenadora científica da I Semana de Música Antiga da UFMG: barroco em contexto (novembro de 2007) e coordena a série Música Antiga no Casarão (Campinas, 2008). 